\title{
Assessing the Environment and Outcomes of Four-Year Aviation Programs: Does Program Quality Make a Difference?
}

\author{
Paul D. Lindseth \\ University of North Dakota
}

\begin{abstract}
The higher education literature concerning academic program quality offers differing opinions as to which indicators should determine program quality (Cameron, 1987; Tan, 1992). Recently, greater attention has been focused upon the environment and the outcomes of higher education academic programs (Astin, 1991). The purpose of this study was to determine to what extent the highest quality U.S. four-year aviation programs follow current literature trends and emphasize environment and outcome indicators of quality. Students $(\mathrm{N}=447)$, faculty $(\mathrm{N}=167)$, and alumni $(\mathrm{N}=577)$ from high, medium, and low quality four-year aviation programs as determined in Lindseth's (1996) study, were surveyed using the Educational Testing Service's Program Self Assessment tool. The instrument measures perceptions of students, faculty, and alumni toward 16 composite characteristics or indicators of academic program quality. Results showed that except for the indicator internship experiences, the emphasis placed on environment and outcome indicators of academic program quality was not significantly different at the highest quality U.S. four-year aviation programs as compared to intermediate and low quality four-year aviation programs.
\end{abstract}

\section{INTRODUCTION}

The overriding theme in the literature concerning academic program quality is that scholars find it hard to agree on which indicators should be used to determine program quality (Cameron, 1987; Tan, 1992). As noted in reviews of research literature (Conrad \& Blackburn, 1985b; Kuh, 1981; Tan, 1992), authors list many indicators that could be classified as input variables to the academic program such as facilities, equipment and dollars. However, an increasing number of environment (process) and outcome variables are being identified as well. For example, Astin's (1985, p. 60-61) "talent-development" concept of educational quality is that "true excellence lies in the institution's ability to affect its students and faculty favorably, to enhance their intellectual and scholarly development, and to make a positive difference in their lives." This view of quality, labeled the value-added view, does focus more on process (environment) and outcome indicators of quality.

Conrad and Pratt (1985) also present questions about processes such as how should an academic program commit resources to the academic processes involved in teaching, research, and service? Examples of these academic processes are faculty-student interactions and development of students' critical thinking and problem solving ability. Kolb's (1984) learning theory and Pace's (1979, 1984, 1990) quality of student effort theory are not factors in most quality ratings. The knowledge gained from research on learning and thinking and how academic programs may adopt curricula to reflect this knowledge is seldom addressed. The 
processes (environment) taking place within the design of an academic program can be very important indicators of program quality. In addition, the "extracurriculum" needs to be considered in an evaluation of academic program quality since the activities of students outside the classrooms certainly may enhance or detract from the overall learning experience of each student (Conrad \& Pratt, 1985; Kuh, Schuh, Whitt \& Associates, 1991). The extracurriculum may include events such as professional group meetings that are held on or nearby the campus.

All of these considerations point to a multidimensional approach in defining indicators of quality academic programs. Furthermore, quality indicators should be examined at the program level as well as the institutional level (Fairweather \& Brown, 1991). According to the higher education literature, (Astin, 1985, 1991; Bogue \& Saunders, 1992; Kuh, 1981; Kuh et al., 1991; Pace, 1990) focusing more on processes and outcomes will help gain a better perspective on the overall indicators of quality in academic programs. Thus to further investigate quality in one specific higher education academic program, the following research study of four-year aviation programs is presented.

\section{Research Design}

The purpose of this study was to determine to what extent the highest quality U.S. fouryear aviation programs follow current literature trends and emphasize environment and outcome indicators of quality. It was a quantitative study of six of the top ten highest quality U.S. four-year aviation programs identified in Lindseth's (1996) study of academic program quality, as well as six randomly selected intermediate quality program and six randomly selected low quality programs. The overall ranking of all 68 U.S. four-year aviation programs
(Lindseth, 1996) was used to select the 18 programs that were studied. From the overall rankings, the six highest quality programs were selected from the top ten programs identified in Lindseth's (1996) study. If one of the 18 aviation programs decided not to participate in the study, the seventh highest ranked program was selected for the top program sample and so forth. For the intermediate and low quality program samples, another program was randomly selected from the applicable category. Intermediate quality programs were those programs rated in the middle one-third of programs and low quality programs were those rated in the lower onethird of programs (Lindseth, 1996). Regardless of what criteria emerged as indicators of quality in Lindseth's (1998) grounded theory study of four-year aviation programs, determining whether the highest quality U.S. four-year aviation programs are following current literature trends and emphasizing environment and outcome variables of program quality seemed essential in a study of academic program quality.

\section{Sample Population}

In this research, the 18 U.S. four-year aviation programs were studied through an Educational Testing Service (ETS) Program Self-Assessment Survey filled out by faculty, students, and alumni from each of the 18 aviation programs. All undergraduate aviation students at each program, classified academically as seniors, comprised the student sample. The assumption was that senior students were better able to judge the program's quality than junior, sophomore, or freshman aviation students. All aviation faculty members at each program comprised the faculty sample. In additions, the 18 four-year aviation programs were asked to provide a list of alumni and their addresses who had graduated from the aviation 
program in the past ten years. A randomly selected sample (using a table of random numbers) of 50 alumni from each program was invited to participate in the study. The completed questionnaires from the faculty, students, and alumni were used to analyze to what extent the highest quality four-year aviation programs emphasize environment and outcome indicators of quality.

\section{Instrumentation}

The ETS's Program Self-Assessment Surveys were used as the measurement instruments. Each ETS instrument addresses whether U.S. four-year aviation programs emphasize key environment and outcome indicators of quality as measured by perceptions of students, faculty, and alumni. The instruments are Likert-scaled measurement instruments consisting of a 62item program quality assessment questionnaire developed by Clark (1983) and the ETS. The instruments were initially developed for graduate programs but were modified for undergraduate academic programs. These instruments were chosen because they measure to what extent students, faculty, and alumni perceive their aviation program emphasizes key environment and outcome variables of program quality. Furthermore, the literature review showed that quality academic programs are shifting their focus from input variables to environment and outcome variables. The 16 composite indicators of quality that the ETS instruments measure are as follows (ETS, 1996):

\section{Environment for Learning}

Extent to which members of the department work together to achieve program goals, provide a supportive environment characterized by mutual respect and concern between students and professors, and are open to new ideas and different scholarly points of view.

\section{Scholarly Excellence}

Perceived scholarly and professional competency of the department faculty, academic ability and efforts of students, and intellectual stimulation in the program.

\section{Quality of Teaching}

Assessment of faculty awareness of new developments in the field, teaching methods, grading procedures, preparation for classes, and interest in assisting students with their academic work.

\section{Faculty Concern for Students}

Extent to which faculty members are perceived to be accessible, interested in the welfare and academic development of students, and aware of student needs, concerns, and suggestions.

\section{Curriculum}

Ratings of the variety, depth, and availability of course and program offerings, program flexibility, opportunities for individual projects, and interactions with related departments.

\section{Departmental Procedures}

Ratings of departmental policies and procedures, such as student participation in departmental decisions, relevance and administration of degree requirements, 

toward the degree, academic and career advisement of students, and helpfulness to graduates in finding appropriate employment.

\section{Available Resources}

Adequacy of available facilities, such as libraries and laboratories, and overall adequacy of physical, financial, and support staff resources; perception of the institution's commitment to the program.

\section{Student Satisfaction with Program}

Self-reported student and alumni satisfaction with the program as reflected in judgments about the amount that has been learned, preparation for intended career, and willingness to recommend the program to a friend.

\section{Internship, Fieldwork, or Clinical} Experiences

Ratings of departmental training, supervision, and assigned duties; contribution of the experiences to academic and professional development; and adequacy of office space and equipment. evaluation of students' progress

financial assistance, and with campus services for nonresident students.

\section{Employment Assistance}

Alumni assessment of the employment assistance received through the department's formal or informal efforts, individual professors, placement office, listings of openings from professional associations, and unsolicited letters sent to employers.

\section{Faculty Work Environment}

Self-reported faculty satisfaction with departmental objectives and procedures, academic freedom, opportunities to influence decisions, and relationships with other faculty members; faculty judgments of departmental management in such areas as planning, administration, and career development of faculty.

\section{Faculty Program Involvement}

Extent to which faculty members report involvement in the program: teaching required courses, participating in policy and curriculum decisions and departmental examinations, directing independent studies, supervising field work or internships, serving as a faculty advisor, and arranging student contacts with nonacademic professionals.

\section{Faculty Research Activities}

Self-reported student satisfaction with opportunities for intellectual and social interaction among persons in the program, with student services and
Extent to which faculty members report receiving awards for outstanding research or scholarly writing, editing professional journals, refereeing articles submitted to 
professional journals, and receiving grants to support research or other scholarly or creative work.

\section{Faculty Professional Activities}

Extent to which faculty members report serving on national review or advisory councils, holding office in regional or national professional associations, and receiving awards for outstanding teaching or professional practice.

\section{Student Accomplishments}

Self-reported student accomplishments in several categories of activity and recognition, including attendance and presentations at professional meetings; writing of scholarly papers, planning and involvement in research projects; development of professional skills and knowledge; recognition through prizes, awards, fellowships, training grants, or scholarships; and participation in department or program planning.

ETS developed similar but separate instruments for students, faculty and alumni. The reliability coefficient alpha for the instruments is $a=.83$ (Clark, 1983) for surveying graduate programs. A pilot test was accomplished on aviation faculty and students to check for reliability of the instruments for undergraduate aviation programs. A test-retest procedure was conducted 14 days apart for both the faculty and students. The faculty instrument testretest correlation coefficient obtained was $.93(\mathrm{p}<.05)$. The student instrument revealed a test-retest correlation coefficient of .83 $(\mathrm{p}<.01)$. With these relatively high values, the instruments appear to be reliable for use in researching program quality in U.S. four-year aviation programs.

To ensure content and construct validity of the instruments, a group of five experts were randomly selected from an official list of Council on Aviation Accreditation (CAA) accreditors received from CAA headquarters. These experts provided feedback as to whether each of the three instruments (faculty, student, and alumni) is a valid measure of four-year aviation program quality. Four of the five experts all agreed that all three instruments were valid measures of quality. The fifth expert was not able to respond due to other professional commitments. However, with four of the experts all in agreement, it was concluded that the instruments would be valid for this particular type of research on four-year aviation programs. The instruments consist of a section on perceptions of program quality and a demographic section. Applicable demographic items, as well as items suggested by the CAA panel of experts, were added to a supplemental section of each instrument.

\section{Data Collection}

The program administrators of each of the 18 aviation programs were contacted by telephone and the importance of the research study was explained along with the protocol procedures. An introductory consent letter was also sent to each administrator clarifying the research study. Two programs in each of the three groups (high, medium, and low quality programs) declined to participate for various reasons, ranging from time constraints on faculty and students to a perception that their input would be of little benefit given their particular circumstances (e.g., program was going to close, unionized faculty were on strike). Thus, two other programs in each 
group were selected and participation approval was obtained.

A research assistant to act in the researcher's behalf was obtained at each of the 18 programs. This was done to insure minimum sampling error and expeditious data collection. The research assistant was either the aviation program administrator, an aviation faculty member, or in one case, a graduate student. Each research assistant received training in regard to the protocol of the research. The assistants were then sent the appropriate number of faculty and senior-level student ETS questionnaires for their respective program. The research assistant distributed the questionnaires to all faculty and senior-level students along with cover letters at a convenient time during the semester. The purpose of the study and directions for the questionnaire were explained in the cover letter. The assistant collected and returned the questionnaires to the researcher, maintaining respondent confidentiality. Some programs were not able to allow class time for the students to complete the questionnaire. In these cases, the response rate suffered somewhat, however no program's response rate dropped below 40\%. Also, some assistants were not as diligent as others to administer and collect the questionnaires. As a result it took four months to receive all the questionnaires.

The response rates for students and faculty were fairly similar between the two groups but within each group the low quality program students and faculty responded at a much higher rate than both the intermediate and high quality program students and faculty. A possible explanation for this may have been greater opportunity by the research assistant to contact faculty and student respondents at the low quality programs due to the program's small size, even though in a previous study program size did not correlate with program quality
(Lindseth, 1996). The overall student response rate was 59\% $(\mathrm{N}=447)$. Students from the highest quality programs responded at a rate of $54 \%(\mathrm{~N}=268)$, while the student response rate from intermediate quality programs was $63 \%(\mathrm{~N}=135)$, and from low quality programs $77 \%(\mathrm{~N}=44)$. The overall faculty response rate was $54 \%(\mathrm{~N}=167)$. The highest quality program faculty responded at a $49 \%$ rate $(\mathrm{N}=119)$, the intermediate quality program faculty responded at a $55 \%$ rate $(\mathrm{N}=31)$, and the low quality program faculty responded at an $88 \%$ rate $(\mathrm{N}=17)$.

The alumni responses were obtained through a mail survey of the ETS alumni questionnaire. Each of the 18 aviation programs did provide a listing of names and addresses of alumni who had graduated with an aviation degree during the past ten years. Fifty respondents were then randomly selected from the alumni lists. Seven programs had not graduated a total of 50 alumni in the past ten years, so all graduates of these programs in the past ten years (the entire population) were surveyed. A cover letter explaining the purpose of the research was sent to each alumnus along with the ETS alumni questionnaire. The overall response rate for the alumni after a postcard follow-up and an additional follow-up letter was $42 \%(\mathrm{~N}=577)$. The response rate for the alumni of the highest quality programs was $42 \% \quad(\mathrm{~N}=286)$, for the intermediate group $40 \% \quad(\mathrm{~N}=154)$, and for the lower quality group $43 \%(\mathrm{~N}=137)$.

\section{Results and Analysis}

The survey data gathered was analyzed utilizing the Statistical Package for Social Sciences (SPSS-X). Scores were analyzed separately for students, faculty, and alumni from each program. The response means, plus or minus the standard deviations for 
students, faculty, and alumni from each program for each applicable indicator of quality from the ETS instruments are displayed in Tables 1, 2, and 3.

\section{Testing for Differences}

To test for significant differences among student $(\mathrm{N}=447)$, faculty $(\mathrm{N}=167)$, and alumni $(\mathrm{N}=577)$ from the highest quality programs, intermediate quality, and lower quality programs, ANOVAs (analysis of variance) were computed using the statistical package SPSS-X. ANOVAs were accomplished for each of the applicable 16 composite indicators of quality on the ETS instrument.

\section{ANOVAs on Student Data.}

Of the eleven applicable student indicators, ANOVA analysis found significant differences in five of the eleven scales. A Scheffe test was accomplished to determine between which groups the means were significantly different. Table 1 displays these differences.

Interpreting the data from this table, three statistically significant determinations can be made. First, students attending intermediate quality aviation programs perceive a more conducive environment for learning and greater student accomplishment than students attending high quality programs. Second, students attending high quality programs perceive greater availability of resources and better internship experiences than students attending either intermediate or low quality aviation programs. Finally, students attending intermediate quality aviation programs perceive greater accessibility to resources than students attending low quality aviation programs. 
Table 1.

Comparison of Means \pm Standard Deviations and ANOVAs for Indicators of Quality as Rated by Students in High, Medium, and Low Quality Programs

\begin{tabular}{|c|c|c|c|c|c|}
\hline & \multicolumn{5}{|c|}{ Students $(\mathrm{N}=447)$} \\
\hline & $\begin{array}{l}\text { High } \\
\text { Quality } \\
\text { Programs } \\
(\mathrm{N}=268)\end{array}$ & $\begin{array}{l}\text { Medium } \\
\text { Quality } \\
\text { Programs } \\
(\mathrm{N}=135)\end{array}$ & $\begin{array}{l}\text { Low } \\
\text { Quality } \\
\text { Programs } \\
(\mathrm{N}=44)\end{array}$ & $\begin{array}{l}\mathrm{F} \\
\text { Value }\end{array}$ & $\mathrm{p}=$ \\
\hline Environment for Learning & $2.93 \pm .43^{\mathrm{a}}$ & $3.10 \pm .45^{\mathrm{a}}$ & $2.97 \pm .44$ & 3.68 & .0267 \\
\hline Scholarly Excellence & $2.98 \pm .43$ & $2.99 \pm .63$ & $2.85 \pm .51$ & & NS \\
\hline Quality of Teaching & $2.97 \pm .45$ & $2.92 \pm .65$ & $2.92 \pm .52$ & & NS \\
\hline Faculty Concern for Students & $2.88 \pm .48$ & $3.04 \pm .57$ & $2.98 \pm .57$ & & NS \\
\hline Curriculum & $2.63 \pm .54$ & $2.52 \pm .71$ & $2.37 \pm .58$ & & NS \\
\hline Departmental Procedures & $2.65 \pm .46$ & $2.69 \pm .62$ & $2.61 \pm .58$ & & NS \\
\hline Available Resources & $2.78 \pm .56^{\mathrm{b}}$ & $2.41 \pm .61^{b}$ & $2.12 \pm .57^{\mathrm{b}}$ & 22.46 & .0000 \\
\hline $\begin{array}{l}\text { Student Satisfaction with } \\
\text { Program }\end{array}$ & $3.32 \pm .60$ & $3.19 \pm .68$ & $3.16 \pm .55$ & & NS \\
\hline Internships & $3.15 \pm .37^{b}$ & $2.90 \pm .32^{b}$ & $2.69 \pm .48^{\mathrm{b}}$ & 8.76 & .0004 \\
\hline Resource Accessibility & $2.37 \pm .60$ & $2.56 \pm .77^{\mathrm{c}}$ & $2.19 \pm .68^{c}$ & 4.31 & .0144 \\
\hline Student Accomplishments & $.38 \pm .17^{\mathrm{d}}$ & $.49 \pm .19^{\mathrm{d}}$ & $.45 \pm .18$ & 9.44 & .0001 \\
\hline
\end{tabular}

NS $=$ Non-significant difference

${ }^{a}$ Significant differences exist between high quality programs and medium quality programs ${ }^{\mathrm{b}}$ Significant differences exist between high quality programs and both medium and low quality programs

${ }^{\mathrm{c}}$ Significant differences exist between medium quality programs and low quality programs

${ }^{\mathrm{d}}$ Significant differences exist between high quality programs and medium quality programs 
ANOVAs on faculty data. Only one of the eleven ETS indicators of quality scales showed significant differences between high, medium, and low quality programs (See Table 2). The environment for learning scale was rated significantly higher by the intermediate quality programs when compared to faculty ratings from the highest quality programs. All other scales showed no significant differences. Thus, the only statistically significant determination that can be made from the faculty questionnaires is intermediate quality program faculty perceive the environment for learning of their respective program at a higher level than faculty at the highest quality programs.

Table 2.

Comparison of Means \pm Standard Deviations and

ANOVAs for Indicators of Quality as Rated by Faculty in

High, Medium, and Low Quality Programs

\begin{tabular}{|c|c|c|c|c|c|}
\hline & \multicolumn{5}{|c|}{ Faculty $(\mathrm{N}=167)$} \\
\hline & $\begin{array}{l}\text { High } \\
\text { Quality } \\
\text { Programs } \\
(\mathrm{N}=119)\end{array}$ & $\begin{array}{l}\text { Medium } \\
\text { Quality } \\
\text { Programs } \\
(\mathrm{N}=31)\end{array}$ & $\begin{array}{l}\text { Low Quality } \\
\text { Programs } \\
(\mathrm{N}=17)\end{array}$ & $\begin{array}{l}\text { F } \\
\text { Value }\end{array}$ & $\mathrm{p}=$ \\
\hline Environment for Learning & $3.05 \pm .39^{\mathrm{a}}$ & $3.35 \pm .38^{\mathrm{a}}$ & $3.20 \pm .45$ & 4.04 & .0211 \\
\hline Scholarly Excellence & $2.96 \pm .44$ & $2.95 \pm .38$ & $3.01 \pm .39$ & & NS \\
\hline Quality of Teaching & $2.91 \pm .55$ & $3.10 \pm .41$ & $3.06 \pm .59$ & & NS \\
\hline Faculty Concern for Students & $3.06 \pm .47$ & $3.29 \pm .39$ & $3.29 \pm .53$ & & NS \\
\hline Curriculum & $2.72 \pm .59$ & $2.68 \pm .69$ & $2.51 \pm .70$ & & NS \\
\hline Departmental Procedures & $2.80 \pm .55$ & $2.99 \pm .46$ & $2.81 \pm .47$ & & NS \\
\hline Available Resources & $2.64 \pm .65$ & $2.36 \pm .61$ & $2.23 \pm .77$ & & NS \\
\hline Faculty Work Environment & $2.86 \pm .46$ & $3.06 \pm .53$ & $3.09 \pm .46$ & & NS \\
\hline Faculty Program Involvement & $1.84 \pm .53$ & $2.04 \pm .90$ & $1.98 \pm .64$ & & NS \\
\hline Faculty Research Activities & $1.81 \pm .23$ & $1.85 \pm .23$ & $1.87 \pm .20$ & & NS \\
\hline $\begin{array}{l}\text { Faculty Professional } \\
\text { Activities }\end{array}$ & $1.67 \pm .32$ & $1.67 \pm .29$ & $1.69 \pm .23$ & & NS \\
\hline
\end{tabular}

NS = Non-significant difference

${ }^{a}$ Significant differences exist between high quality programs and medium quality programs 
ANOVAs on alumni data. For the ETS questionnaire sent to alumni, there were ten applicable indicators of quality. ANOVA analysis found significant differences in only two of the ten scales among the three groups of alumni. The two scales where significant differences were found were available resources and internships. A Scheffe test was done to determine between which groups the means were statistically significant. Table 3 displays these differences. From the data in Table 3, two statistically significant determinations can be made. The first addresses the indicator available resources. Alumni who attended the highest quality programs perceive they had greater availability of resources than alumni who attended either intermediate or low quality programs. Second, alumni graduating from high quality programs perceive greater benefit from their internship experiences than alumni graduating from low quality programs.

\section{Table 3.}

Comparison of Means \pm Standard Deviations and ANOVAs for Indicators of Quality as Rated by Alumni in High, Medium, and Low Quality Programs

\begin{tabular}{|c|c|c|c|c|c|}
\hline & \multicolumn{5}{|c|}{ Alumni $(\mathrm{N}=577)$} \\
\hline & $\begin{array}{l}\text { High } \\
\text { Quality } \\
\text { Programs } \\
(\mathrm{N}=286)\end{array}$ & $\begin{array}{l}\text { Medium } \\
\text { Quality } \\
\text { Programs } \\
(\mathrm{N}=154)\end{array}$ & $\begin{array}{l}\text { Low } \\
\text { Quality } \\
\text { Programs } \\
(\mathrm{N}=137)\end{array}$ & $\begin{array}{l}\mathrm{F} \\
\text { Value }\end{array}$ & $\mathrm{p}=$ \\
\hline Environment for Learning & $2.98 \pm .41$ & $2.94 \pm .43$ & $2.78 \pm .57$ & & NS \\
\hline Scholarly Excellence & $2.88 \pm .58$ & $2.72 \pm .59$ & $2.82 \pm .62$ & & NS \\
\hline Quality of Teaching & $2.95 \pm .53$ & $2.79 \pm .59$ & $2.85 \pm .61$ & & NS \\
\hline Faculty Concern for Students & $2.98 \pm .54$ & $2.87 \pm .59$ & $2.93 \pm .70$ & & NS \\
\hline Curriculum & $2.42 \pm .65$ & $2.29 \pm .70$ & $2.38 \pm .63$ & & NS \\
\hline Departmental Procedures & $2.43 \pm .58$ & $2.37 \pm .63$ & $2.39 \pm .60$ & & NS \\
\hline Available Resources & $2.90 \pm .58^{\mathrm{a}}$ & $2.25 \pm .67^{\mathrm{a}}$ & $2.26 \pm .63^{\mathrm{a}}$ & 30.06 & .0000 \\
\hline $\begin{array}{l}\text { Student Satisfaction with } \\
\text { Program }\end{array}$ & $3.03 \pm .73$ & $2.82 \pm .74$ & $3.00 \pm .76$ & & NS \\
\hline Internships & $3.03 \pm .60^{\mathrm{b}}$ & $2.70 \pm .54$ & $2.56 \pm .74^{\mathrm{b}}$ & 5.95 & .0035 \\
\hline Employment Assistance & $1.32 \pm .63$ & $1.27 \pm .79$ & $1.40 \pm .59$ & & NS \\
\hline
\end{tabular}

NS = Non-significant difference

${ }^{a}$ Significant differences exist between high quality programs and both medium and low quality programs

${ }^{b}$ Significant differences exist between high quality programs and low quality programs 


\section{DISCUSSION OF RESULTS AND ANALYSIS}

\section{Similar Emphasis on Environment and Outcome Indicators of Quality}

This study focused on the environment and outcomes of U.S. four-year aviation programs. All of the ETS instrument scales examined environment and outcome variables to some extent except for the available resources scale. The environment and outcomes of four-year aviation programs are very important when using the ETS Program Self Assessment Survey tool.

In examining the mean scores by students, faculty, and alumni for each indicator of quality scale, as well as the totaled average student, faculty, and alumni mean score, several intermediate quality program means were higher than the high quality program means. Some of the low quality program means were also higher than the high quality program means. But why did this happen? Does this data invalidate previous research findings? A reason for the different results is because program quality was measured in another way in this study, (e.g., through the ETS survey instruments). When analyzing student, faculty, and alumni group means for significant differences, the results show that the highest quality aviation programs do not emphasize environment and outcome variables as indicators of quality, at least to no greater extent than the intermediate and low quality programs. In a few cases, the highest quality programs actually emphasize environment and outcome variables to a lesser extent.

However, to show that the differences are not very extensive among students, faculty, and alumni at the three groups of U.S. four-year aviation programs (high, medium, and low), additional comparisons were made. For example, among students, only five of the eleven applicable ETS indicators of quality scales showed significant differences between high, medium, and low quality program groups. Only two of these scales, available resources and internships, showed significant differences between students in the highest quality programs compared to students in both the medium quality programs and low quality programs. The internship scale measured an environment variable whereas the available resources scale was an input variable. On the other hand, the environment for learning and the student accomplishment scales were rated significantly higher by the intermediate quality group over the high quality group. Furthermore, although not significantly higher, the rated mean for these scales by the low quality group was also higher than the high quality group of aviation programs. The last significantly different rating in the student sample was on the scale resource accessibility. The medium quality program group rated it significantly higher than the low quality program group. Thus, only one of the eleven student ETS indicators of quality scales measuring environment or outcome variables was rated significantly higher by the highest quality programs. According to the students, it could be concluded that the highest quality four-year aviation programs are not emphasizing environment and outcome variables that are indicators of quality to any greater extent than intermediate or low quality aviation programs.

The survey completed by faculty from high quality, medium quality, and low quality programs found ten of the eleven indicators of quality scales had no significant differences between groups. The only significant difference appeared in the environment for learning scale. The 
intermediate quality program faculty rated their environment for learning significantly higher than the high quality program faculty. The low quality program faculty also rated this scale higher than the high quality program faculty, although not significantly. These results overwhelmingly indicate that according to the faculty, the highest quality programs are not emphasizing environment and outcome variables of indicators of quality to any greater extent than the intermediate or low quality program.

When examining the results from the alumni sample, the conclusions are similar to the student data. Of the ten applicable ETS instrument indicators of quality scales, two were found to have significant differences between alumni groups. These scales were available resources and internships. The available resources scale, an input variable scale, was rated significantly higher by the high quality program alumni as compared to both the medium quality and low quality program alumni. Similar to the student ratings, the internship scale was rated significantly higher by the high quality program alumni as compared to the low quality program alumni. Although the medium quality program alumni's mean rating on this scale was also lower than the high quality program alumni, it was not significant. Thus, just like the student category, the only indicator of quality scale rated significantly higher by the high quality programs that measures environment or outcome variables was the internship scale.

\section{CONCLUSION}

Considering the opinions from students, faculty, and alumni, the highest quality U.S. four-year aviation programs do not emphasize environment and outcome indicators of quality to any greater extent than intermediate and low quality aviation programs. According to the surveys from students, faculty, and alumni, the only area where more emphasis is placed by the highest quality programs on environment or outcome indicators of quality is the area of internship experiences. This emphasis should be maintained at the highest quality programs and the other programs should consider increasing emphasis in this area since the aviation industry experts placed a great deal of importance on performance of graduates, and generally speaking, these graduates had come from four-year aviation programs with very active internship programs. Thus, even though from previous research (Lindseth, 1996) aviation education experts generally agreed on which programs were of highest quality, only one of the environment and outcome indicators of quality focused upon in this study were emphasized to a greater extent at the highest quality programs when compared to the intermediate and lower quality programs. Based upon the results of this study, further research should be done on the importance of the internship experience as well as the importance of the environment for learning within collegiate aviation academic programs. 